\title{
Pardo Agudín en la defensa de Nador
}

\author{
ENRIQUE Gudín DE LA LAMA \\ Universidad Internacional de la Rioja \\ enrique.gudin@unir.net
}

Recibido: 02/12/2013

Aceptado: 30/06/2014

\section{RESUMEN}

En los días terribles de Annual, la defensa de Nador fue uno de los episodios que despertó sentimientos de admiración por lo heroica que había sido. Sin embargo el teniente coronel Pardo Agudín pasó de solicitar la Laureada a verse encausado en un consejo de guerra que se fundamentaba, precisamente, en los mismos motivos por los que solicitaba la Laureada. El consejo de guerra lo absolvió, pero, pasado el tiempo y una vez fallecido, la Laureada le fue denegada.

Este artículo procura esclarecer tanto la actuación del teniente coronel como las resoluciones de los tribunales a la luz de fuentes primarias que han sido poco utilizadas hasta hoy.

Palabras clave: Annual, Juntas de Defensa, Laureada de S. Fernando, defensa de Nador, Guerra del Rif.

\section{Pardo Agudín rol in the defense of Nador}

\begin{abstract}
In the terrible days of Annual, the defence of Nador was one of the episodes that aroused feelings of admiration because of its heroism. But Lieutenant Colonel Pardo Agudín went over requesting the Laureada to being prosecuted in a martial court, based precisely on the same reasons for requesting the Laureada. The martial court acquitted him, but, over time and after his death, the Laureada was denied. This article tries to clarify the action of the lieutenant colonel as well as the resolutions of the courts in the light of primary sources which have been scantly used until nowadays.
\end{abstract}

Key words: Annual, Boards of Defence (Defence's Juntas), Saint Ferdinad's Laureada, Defence of Nador, Rif War.

Sumario ${ }^{1}$ : 1. Introducción. El Ejército y Marruecos en la crisis de la Restauración. 2. El Desastre, primeras reacciones. 3. Pardo Agudín y la defensa de Nador. 4. La solicitud de la Laureada. 5. Otros puntos de vista de lo sucedido en Nador. 6. El consejo de guerra. 7. La campaña de reconquista. militares vs. militares. 8. El socorro a Nador, Zeluán y Monte Arruit. 9. La viuda de Pardo Agudín retoma el expediente. 10. Un héroe fuera de plazo no es héroe. 11. Conclusiones.

\footnotetext{
1 Abreviaturas utilizadas: Archivo General Militar de Madrid (AGMM); Archivo General Militar de Segovia (AGMS); Archivo Histórico Nacional (AHN). 


\section{Introducción. El Ejército y Marruecos en la crisis de la Restauración}

Son abundantes los estudios que se han realizado en torno a las relaciones entre civiles y militares en la época contemporánea: los elementos que influyen en ellas y las condicionan, el papel de los militares en la sociedad, su integración o aislamiento respecto a ella y sus planteamientos vitales, pues, tal como sugería Huntington, la militar no es una profesión sin más, neutra, sino "vocacional”, con sentido de misión, de historia y de nación. Y son, precisamente, las contradicciones entre intenciones, fines y designios de los militares y los valores de la sociedad lo que genera las enormes dificultades de acoplamiento entre el sistema militar y lo político y social ${ }^{2}$, pues aún sabiéndose parte de una sociedad determinada, se han sentido diferentes a ella, pero con una misión concreta respecto a esa sociedad.

Durante la época de la Restauración se aceptaba que los militares participasen en política; sin embargo los que lo hicieron fueron una minoría, normalmente jefes y generales. La mayoría de los miembros del Ejército podrían considerarse "apolíticos" en el sentido en el que utiliza el término Huntington ${ }^{3}$, es decir, un colectivo con intereses diversos del poder civil. No obstante, y siguiendo el análisis que hace Cruz, en la España de aquella época se había ido conformando un Ejército "cuyos intereses consistieron en garantizar la supervivencia estatal -y de su propia organización-, en los términos de una autonomía relativa respecto de la población" ". Por su parte Payne y Boyd hablan de "pretorianismo". En cambio, Payne "se refiere específicamente a la intervención del Ejército en la política y en el Gobierno civiles con fines primariamente civiles - es decir, políticos-, más relacionados con problemas nacionales y políticos que con ambiciones militaristas propiamente dichas" "; Boyd, por su parte, considera como puntos clave las dobles relaciones entre profesionalización militar y modernización política y descontento militar y debilidad civil ${ }^{6}$.

2 Cfr. HUNTINGTON, Samuel P.: The soldier and the state: The theory and politics of civil-military relations, Harvard University Press, 1957; JANOWITZ, Morris: The Professional Soldier: A Social And Political Portrait, Free Press, 1964; FERNÁNDEZ SEGADO, Francisco: Fuerzas Armadas-Sociedad: del mutuo aislamiento a la progresiva integración, Reis, 1986, pp. 35-76; BUSQUETS, Julio: El militar de carrera en España. Barcelona, Ariel, 1984; HARRIES-JENKINS, Gwyn. "The concept of military professionalism" en Defense Analysis, vol. 6, 2 (1990), pp. 117-130.

3 HUNTINGTON, Samuel P.: The soldier and ... p. 226. Cfr. tb el análisis de Carlos Navajas en: NAVAJAS ZUBELDIA, Carlos: “Ejército y sociedad en España, 1923-1930”, en Berceo, 116-117 (1989), pp. 157-170.

4 CRUZ, Rafael: "La lógica de la Guerra. Ejército, Estado y Revolución en la España Contemporánea”, en Studia Histórica-Historia Contemporánea, vol X-XI (1992-93), pp. 207-222.

5 PAYNE, Stanley. Ejército y sociedad en la España liberal (1808-1936), Madrid, Akal, 1977, p. 12.

6 BOYD, Carolyn P.: Praetorian Politics in Liberal Spain, Chapell Hill, The University of North Carloline Press, 1979. 


\section{7: junteros y africanistas ${ }^{7}$}

En 1917 se produjo la primera crisis seria del sistema de la Restauración. Emergieron durante el verano y el otoño de aquel año los conflictos larvados que se habían ido fraguando a lo largo de los últimos años: la Asamblea de Parlamentarios, la huelga general y las Juntas Militares. Aparentemente esos sucesos no fueron a más, pero los problemas que habían sacado a la luz continuaron creciendo, el régimen empezaba a descomponerse.

Por lo que se refiere al Ejército, fue clave el papel que desempeñaron las Juntas Militares. Inicialmente sus objetivos se centraban en oponerse al sistema de promoción por méritos de guerra y a la camarilla palaciega de Alfonso XIII. Por otra parte, manifestaban abiertamente su desconfianza hacia los políticos y pedían pagas más altas. Sin embargo, apenas mencionaban los problemas profesionales que aquejaban al Ejército. Las juntas tomaron carta de naturaleza con la aprobación en diciembre de 1917 de la Junta Central de Defensa. Incluso puede decirse que consiguieron en buena medida sus objetivos cuando en junio de 1918 las Cortes aprobaron el proyecto de reforma del Ejército.

Aunque cuando se alude a ellas se tiende a resaltar la pugna entre africanistas y peninsulares o destacar el debate entre escala cerrada y ascensos por méritos de guerra, más destacable que ello es el hecho en sí de que hubiese división en el Ejército, y esa división tenía mucho que ver con las cotas de poder que pretendían alcanzar unos u otros jefes y oficiales. No hay más que pensar en el cambio de criterio de Burguete respecto a la política marroquí tras su nombramiento como Alto Comisario, o el cambio de posición del propio Primo de Rivera, también en lo que se refiere a la política marroquí una vez alcanzado el poder. De alguna forma, lo que el problema de Marruecos supuso para el Ejército fue bastante más que el debate de los ascensos por méritos de guerra. A medida que la guerra se iba enquistando fueron surgiendo nuevos problemas que iban desde la escasa eficiencia de la burocracia militar, la escasa preparación de las tropas, la necesidad de aumentar el reclutamiento, el insuficiente equipamiento de las tropas, de los Cuerpos y de las Armas, el escaso presupuesto (para un desmesurado Ejército peninsular), el caos burocrático y administrativo del Protectorado, más el afán de protagonismo o de "distinguirse" de algunos mandos "africanos"

\footnotetext{
7 Sobre esos dos "tipos" de militar, la bibliografía es amplia. Algunas de las interpretaciones más significativas sobre sus planteamientos y personalidad en: PAYNE, Stanley G. Los militares y la politica en la España contemporánea, Madrid, Sarpe, 1986; BUSQUETS, Julio y LOSADA, Juan Carlos: Ruido de sables. Las conspiraciones militares en la España del siglo XX, Barcelona, Crítica, 2003; BOYD, Carolyn P.: Praetorian Politics in Liberal Spain, Chapell Hill, The University of North Carloline Press, 1979; CARDONA, Gabriel. El poder militar en la España contemporánea hasta la guerra civil, Madrid. Siglo XXI, 1983; MADARIAGA, María Rosa: En el barranco del lobo. Las guerras de Marruecos, Alianza, Madrid, 2011; SECO SERRANO, Calos: Militarismo y civilismo en la España contemporánea, Madrid, Instituto de Estudios Económicos, 1984. SECO SERRANO, Carlos: Alfonso XIII y la crisis de la Restauración, Madrid, Rialp, 1989.

8 Rosa Madariaga hace un análisis certero de los sucesivos conflictos que hubo en aquellos años en el seno del Ejército en MADARIAGA, María Rosa: En el barranco del..., pp. 250-331.
} 


\section{Marruecos, un problema de todos ${ }^{9}$}

No obstante, Marruecos no sólo fue un problema militar, fue el problema que muchos historiadores han identificado como el principio del fin del sistema de la Restauración ${ }^{10}$. En primer lugar fue un problema que ató al Rey ${ }^{11}$-él mismo se comprometió con la aventura marroquí socavando la autoridad civil frente a las reivindicaciones militares ${ }^{12}-$, contribuyó a acelerar la inestabilidad política del régimen, pues cada operación militar que se acometía era fuente de ansiedad -y de indecisión- para el Gobierno de turno y, por último, fue origen también de turbulentas reacciones por parte de la opinión pública. "Se trataba, en realidad, de un problema con una doble vertiente. Por una parte, la continua y creciente inestabilidad política del régimen impedía la aplicación de políticas coloniales estables y continuadas. Por otra, la inestable situación colonial nacida de esta falta de dirección desembocaba con frecuencia en situaciones comprometidas de las que acabaron siendo víctimas nuevos Gobiernos -el Gabinete Allende-Salazar en 1921, los de Maura y Sánchez Guerra en 1922 y el de García-Prieto en $1923-{ }^{13}$. Marruecos se acabó convirtiendo en el eje de la política nacional dando lugar a un estado de creciente crispación política y un recrudecimiento de la tensión entre poder civil y militar, especialmente a partir de Annual, a medida que la exigencia de responsabilidades iba alcanzando esferas que se habían creído a salvo ${ }^{14}$. En cuanto a su impacto dentro del Ejército, Annual agravó la crispación entre junteros y africanistas: mientras unos achacaban al afán de protagonismo y a las ambiciones expansionistas de los africanistas el fracaso de Annual, los otros acusaban a los junteros de ser los responsables de la laxitud y corrupción existentes en Marruecos y la escasa preparación de los reclutas que se incorporaban al frente. Por otra parte, como no acababan de exigirse responsabilidades a los políticos, el sentimiento de agravio comparativo entre los militares se intensificó, y se sumó a ello la percepción de que el poder político continuaría siendo inoperante en la resolución del problema marroquí.

9 Una obra colectiva reciente sobre el protectorado de Marruecos en la que intervienen los principales especialistas actuales sobre el tema: ARAGON REYES, Manuel (dir.): El Protectorado español en Marruecos: la historia trascendida, Bilbao, Iberdrola, 2013.

10 No es preciso señalar que los principales autores de referencia comparten esta opinión aunque en sus exposiciones cada uno ponga el acento en una u otra cuestión: FERNÁNDEZ ALMAGRO, M. Historia del reinado de Alfonso XIII, Barcelona, Barcelona, 1934; GARCÍA DELGADO, J.L. (ed.) La crisis de la restauración. España, entre la Primera Guera Mundial y la II República, Madrid, 1986; SECO SERRANO, Carlos: La España de Alfonso XIII. El Estado y la política. (1902-1931). T. XXXVIII de la Historia de España de Menéndez Pidal. Madrid, 1995.

11 LA PORTE, Pablo: "Marruecos y la crisis de la Restauración 1917-1923”, Ayer 63 (2006), pp. 53-74.

12 LARIO, Ángeles: "Historia y monarquía. Situación historiográfica actual", Historia Constitucional, 6 (2005), p. 409-425.

13 LA PORTE, Pablo: "Marruecos y la crisis...", pp. 53-74.

14 Es de gran ayuda para hacerse cargo de la complejidad del problema el libro de PRIETO, Indalecio: Con el Rey o contra el Rey. México, Oasis, 1972. En el se reúnen los artículos e intervenciones públicas de Prieto al respecto. Analiza el problema desde sus planteamientos (periodísticos e ideológicos), lo que facilita la comprensión de la postura que intentó llevar más lejos la petición de responsabilidades. Por su parte, Ángeles Lario sostiene que "la razón del poco cuerpo de los partidos políticos y del papel de las Cortes, siempre supeditado al Gobierno, creo que es el que mejor nos puede hacer entender los fracasos que se hicieron evidentes en los años 20 y 30." LARIO, Ángeles: "Historia y monarquía...", pp. 425 
Por último, la opinión pública también fue un componente de peso en la evolución del problema de Marruecos. Tras el fracaso de Cuba, las campañas de Marruecos no contaron inicialmente con el apoyo popular, más bien todo lo contrario, y fueron aprovechadas, además, como detonante para desencadenar tensiones y reivindicaciones sociales (Semana Trágica). No obstante, Annual supuso una sacudida tal que la opinión pública se situó incondicionalmente del lado del Gobierno, pese a que los sucesivos Gabinetes no fueron capaces de resolver los problemas que más preocupaban a la opinión pública: "la recuperación de las posiciones perdidas, el castigo a los rebeldes, la liberación de los prisioneros españoles, el fin de las campañas militares, la repatriación de los soldados y la exigencia de responsabilidades políticas. Una a una, todas las esperanzas que se habían creado a la sombra de la derrota de Annual se vieron aplazadas y desvirtuadas" ${ }^{15}$. Pasados los primeros meses y ante el estancamiento de la situación militar y las constantes maquinaciones de unos y otros para eludir las propias responsabilidades y cargárselas a los demás, se fue deteriorando la confianza en las instituciones parlamentarias y de Gobierno. Ese creciente malestar se fue concentrando sobre los políticos que, rendidos a él, acabaron paralizando su propia acción de Gobierno.

\section{Las responsabilidades de Annual, un tema todavía abierto}

La exigencia de responsabilidades pasó del ámbito militar al político al cabo de pocos meses. El Gobierno durante los sucesos de Annual, presidido por el conservador Allendesalazar, fue sucedido por otro encabezado por Maura que ordenó las operaciones de reconquista del territorio perdido. Pero las diferencias entre los ministros en torno a la política a seguir en el protectorado provocaron la dimisión del propio Maura en marzo de 1922. Le sucedió Sanchez Guerra, también conservador, que detuvo las operaciones militares, ordenó la disolución de las Juntas de Defensa, orientó el protectorado hacia el control civil, y envió al Parlamento el "expediente Picasso". En ese momento se abrió el debate de las responsabilidades civiles. Conducido por la minoría socialista de la mano de Indalecio Prieto, el debate apuntó hacia la Corona, en un ataque frontal al sistema. Los enfrentamientos en las Cortes llevarían a la dimisión del Gobierno Sánchez Guerra y a la vuelta al poder de los liberales de la mano de García Prieto. Su programa incluía el nombramiento de un civil como alto comisario y el procesamiento de las responsabilidades. Pronto, sin embargo, surgieron discrepancias entre los propios ministros respecto a la política de seguir en Marruecos. La indecisión del Gobierno ante la posibilidad de que el Ejército realizase un ataque firme sobre Abd-el-Krim y el pago del rescate de los prisioneros capturados en 1921, provocaron un enorme descontento en el Ejército. Finalmente, García Prieto aceptó formar una comisión para dirimir las acusaciones contra el Ejército, los políticos y el Rey. Pero el informe de la comisión no llegaría a las Cortes, antes se produciría el golpe de estado del general Primo de Rivera.

A pesar del tiempo transcurrido -casi un siglo- desde el desastre de Annual, aún es posible aclarar algún aspecto; en concreto, alguna actuación que en su día, merced a

\footnotetext{
15 LA PORTE, Pablo: "Marruecos y la crisis...", pp. 53-74.
} 
la intensa polémica que generó el Desastre, quedó primero desvaída, después desfigurada y finalmente escondida en los entresijos de las declaraciones de quienes -militares, políticos y periodistas- ocuparon aquellos años las primeras planas de los periódicos y las tribunas de oradores. Después, pasado el tiempo, las obras de divulgación y los artículos para el gran público se conforman con reproducir las consideraciones de los documentos más famosos de aquella época -el Informe Picasso, la Comisión de Responsabilidades o la selección de crónicas de periodistas destacados- dejando de lado fuentes primarias tan determinantes como el Archivo General Militar de Madrid y su sección de África, y el Archivo General Militar de Segovia, donde se conservan los expedientes de las Laureadas que se incoaron en aquellos años.

El teniente coronel Pardo Agudín, jefe de la defensa de Nador, ha pasado a la Historia con más sombras que luces a pesar de que en su momento fue considerado como un héroe ${ }^{16}$. Ha sido uno de los sepultados para la historia, tanto por las declaraciones de los protagonistas mediáticos de aquella época, como por los vientos polémicos que soplaron en aquellos años. Sin embargo, a la luz de su expediente de la Laureada y de algunos de los partes que se escribieron en aquellos días, no cabe duda de que su conducta en la defensa de Nador fue heroica.

\section{EI Desastre, primeras reacciones}

La mañana del 22 de julio de 1921 comenzó la retirada de Annual. Había sido precedida un mes y medio antes por la desastrosa operación de Abarrán y por los inútiles esfuerzos en los días inmediatamente anteriores de socorrer Igueriben, presenciados por las tropas -unos cinco mil hombres- estacionadas en Annual. Lejos de sus posiciones y sin posibilidad de un apoyo logístico eficaz, el general Silvestre se encontraba en el collado de Annual a merced de las tropas de Abd el-Krim. Su reacción ante el acoso fue una orden de repliegue hacia Melilla que se inició con gran desorden. Cundió el pánico y la retirada se convirtió en una huida aterrorizada. En un trágico "efecto dominó" fueron cayendo todas las posiciones de la Comandancia de Melilla. El balance final fue de diez mil muertos. Las reacciones de los mandos durante aquellos días han sido analizadas muchas veces. El Informe Picasso es el documento más conocido: una investigación exhaustiva y rigurosa que comenzó a elaborarse cuando la tragedia todavía no se había cerrado. También hubo periodistas y reporteros destacados en Melilla que siguieron e informaron de los acontecimientos casi desde el mismo momento en que empezaban a producirse. El día 23 de julio ya aparecían en prensa nacional las primeras noticias apuntando la magnitud del desastre ${ }^{17}$.

16 Es significativa la atención que dedica Ramón J. Sender al episodio: SENDER, Ramón J.: Imán, Madrid, Destino, 2001, pp. 202-224. El autor dedica todo el capítulo 11 de Imán, su conocida novela sobre el desastre de Annual, a la defensa de Nador. De estilo realista y algo crudo, en el episodio queda manifiesta la heroicidad de los defensores de la Fábrica de Harinas. Imán fue publicada por primera vez en 1930, lo que indica que, a pesar de la intensa polémica sobre Annual de aquellos años, la percepción que aún se mantenía sobre la defensa de Nador seguía siendo positiva, lo cual es más significativo en un autor tan crítico con la guerra de Marruecos como Sender.

17 La Correspondencia militar, El Heraldo de Madrid, El Siglo futuro, del 23/07/1921 hablan de graves sucesos en Melilla, del asalto a la posición de Annual, alguno de ellos aventura la muerte de Silvestre y reseñan 
A partir de ese momento el conocimiento de los sucesos y las conjeturas que se fueron haciendo sobre ellos discurrieron en paralelo condicionando las sucesivas intervenciones tanto militares como políticas. El 4 de agosto el Gobierno nombró al general Picasso para que investigase lo que había sucedido y depurase responsabilidades ${ }^{18}$. Éste se trasladó inmediatamente a Melilla para comenzar su tarea; al mismo tiempo se ponían en marcha los consejos de guerra que juzgasen las conductas poco honrosas de jefes y oficiales y se incoaban los expedientes de recompensas para quienes habían mostrado una conducta heroica.

Las diversas circunstancias generadas por el Desastre facilitaron que empezasen a manifestarse abiertamente en el Ejército rencillas que hasta entonces habían permanecido latentes y que encontraran ahora diversos cauces para su expresión. Por ejemplo, algunos generales -Burguete, Luque, Weyler-, con la sociedad española todavía aturdida por el Desastre, no tuvieron inconveniente en criticar abiertamente desde la prensa los planteamientos con que se habían llevado a cabo las operaciones. El ministro de la Guerra acabó prohibiendo a los militares todo comentario público, pero eso no impidió que Burguete se hiciese notar de nuevo al protestar por el nombramiento de Cavalcanti como comandante general de Melilla, menos veterano que él en el cargo.

A mediados de septiembre de 1921 el Rey nombró gentileshombres de cámara a Millán Astray (de la Legión) y Gonzalez Carrasco (de Regulares). Las Comisiones Informativas -antiguas Juntas- criticaron los nombramientos por considerarlos unos ascensos disimulados. También sentó mal entre las Comisiones una Real Orden del ministro de la Guerra en la que se reservaba la elección de los jefes y oficiales que habían de cubrir las vacantes en Marruecos. Pero no tuvieron inconveniente en hacerse presentes en los procedimientos judiciales y en las investigaciones del general Picasso. Varios oficiales vinculados a las Comisiones acudieron a Melilla para "interesarse" por la suerte de los oficiales encausados afines a las Comisiones Informativas.

La llegada de fuerzas expedicionarias a Melilla también fue motivo de desavenencias entre oficiales. Algunos de los que llegaban no podían dejar de "manifestar" su menosprecio hacia quienes habían perdido el territorio y las tropas que tenían encomendadas.

\section{Pardo Agudín y la defensa de Nador}

En ese ambiente, el 2 de agosto de 1921, fue recibido en Melilla (y en España) el teniente coronel Pardo Agudin y los hombres con los que estuvo defendiéndose durante nueve días en la fábrica de harinas de Nador. Francisco Pardo Agudín tenía en aquel momento 46 años. Hijo de un capitán de Carabineros, había ingresado en el Ejército como soldado voluntario de Infantería en junio de 1892, tres meses después pasó a la Academia General Militar y un año más tarde a la academia de Infantería, de donde

también la petición de refuerzos. $A B C$ 24/07/1921 habla de la muerte de Silvestre. El Imparcial de ese día, titula su portada: "La columna del comandante general de Melilla a punto de ser copada por los moros" y en el subtítulo habla del suicidio del general Fernández Silvestre.

18 Real Orden de 4 de agosto de 1921. AHN. FC-Tribunal Supremo - Reservado, Exp.50, N.1 
salió como segundo teniente en 1895. Desde su primer destino, el Regimiento de Infantería Zamora $\mathrm{n}^{\mathrm{o}} 8$, fue enviado en un batallón expedicionario a Cuba, en donde estuvo casi dos años. Su participación en diversas acciones de combate le hizo acreedor en tres ocasiones de la cruz de primera clase del mérito militar con distintivo rojo. También resultó herido en una ocasión y acabó volviendo a la Península en diciembre de 1897, fecha a partir de la cual fue pasando por diversos destinos (La Coruña, Valladolid, Zaragoza, Soria, etc.) hasta que el 11 de marzo de 1921 fue destinado a la Brigada Disciplinaria de Melilla ${ }^{19}$.

La primera reconstrucción de lo que había sucedido en Nador la hizo el mismo 2 de agosto de 1921 el propio teniente coronel $\mathrm{Pardo}^{20}$; se trataba del extenso parte que dirigió al Estado Mayor de la Comandancia de Melilla. En él contaba cómo el 22 por la tarde fue convocado en la Comandancia General a una reunión de Jefes de Cuerpo donde les comunicaron la muerte del comandante general y la retirada de Annual, y se tomaron las medidas para lo que se preveía que podía suceder. El teniente coronel Pardo advirtió al coronel jefe de Estado Mayor -coronel Sánchez Monge- que Nador ni estaba en estado de defensa ni tenía guarnición propiamente dicha; la contestación fue que era difícil que el enemigo llegase hasta allí.

A lo largo del día 23, fueron atravesando el poblado partidas de soldados que procedían de las distintas posiciones y se dirigían a Melilla. La población civil de Nador se inquietó y comenzó a evacuar el poblado. Esa noche el teniente coronel solicitó varios trenes con los que evacuar los 140 enfermos que tenía en la enfermería militar. Aunque desde la Comandancia le aseguraban que no había peligro, las noticias que trasmitía la riada de gente que pasaba camino de Melilla impulsaron al teniente coronel Pardo a buscar refuerzos. No consiguió nada.

“Así lo hice saber a Comandancia General telefónicamente, y que me vería precisado de abandonar el poblado y cubrir la retirada del convoy que se formara hacia Melilla. Entonces se me ordenó que procurase detener los soldados fugitivos y organizase una defensa". ${ }^{21}$

Esa noche montó guardia en la iglesia un destacamento compuesto por unos 20 hombres, la mayoría guardias civiles bajo el mando del teniente Fresno, jefe de la línea. En medio del caos y el desbarajuste, al amanecer del día 24 había conseguido reunir algunos hombres. Habló por teléfono con el capitán Ortoneda, de la Policía Indígena y decidieron que el mejor sitio para hacerse fuertes era la llamada "Fábrica de Harinas". El capitán acudiría allí con los hombres de su guarnición que pudiese reunir mientras el teniente coronel, después de que saliese el último tren para Melilla.

“[...] ordené la ocupación de la casa de la "COMPAÑÍA COLONIAL DE INDUSTRIA Y COMERCIO", o Fábrica de Harina y Electricidad en el momento preciso en que los moros del poblado indígena rompían el fuego desde las lomas y alturas próxi-

\footnotetext{
19 Documentación relativa a Francisco Pardo Agudín. AGMS. Sección 1. Leg P. 440.

20 Defensa y evacuación de Nador desde el 22 julio 1921 al 2 agosto siguiente. AGMM. Africa. Leg. 264. carp. 32 .

21 Ibid.
} 
mas sobre las acciones e individuos sueltos que a la carrera se acogían al edificio. El Comandante Jefe de Armamento de la Brigada D. Wenceslao Sahún Navarro dada la rapidez y urgencia con que recibió la orden de acogerse a la Fábrica y ante la imposibilidad de retirar el armamento y municiones de su cargo que existían en el Almacén del Cuerpo y de acuerdo con el Capitán de este cometido, D. Celestino Rey Joly prendió fuego al barracón almacén que lo contenía bajo el fuego de fusilería enemiga, retirándose precipitadamente a la Fábrica protegido por una guerrilla", ${ }^{22}$

Una vez instalados en la fábrica, se organizó la defensa en dos compañías que se situaron en el piso de arriba mientras en el piso bajo se puso la enfermería. El acoso enemigo se intensificó y a media mañana fue muerto el comandante Sahún. Para alimentarse aprovecharían la harina de cebada que había almacenada: las mujeres y los paisanos que se habían refugiado con ellos en la fábrica fueron elaborando tortas. Por la tarde de ese día vieron pasar un aeroplano en dirección Zeluán-Melilla ${ }^{23}$; debió tratarse del Bristol Tourier pilotado por Hereward De Havilland que llevaba a bordo a José Espinosa, periodista de "El Liberal" y que acabó aterrizando junto al fuerte de Cabrerizas Altas.

A lo largo de la noche continuaron recibiendo disparos. Cuando amanecía el día 25 presenciaron desde la fábrica de Harinas como se acercaba un tren que enseguida tuvo que retroceder ante la intensidad del acoso que sufrió. Por la tarde recibieron un ataque general en toda regla. El enemigo llegó tan cerca que intentó en dos ocasiones incendiar el edificio lanzando sacos de paja impregnados de petróleo y consiguió meter dos granadas de mano a través de las ventanas del piso bajo que no llegaron a explotar. El balance del tiroteo fue un muerto y varias bajas.

El día 26 recibieron por heliógrafo dos mensajes:

“A las 16:30.- S.D. N 6.- El General Sanjurjo a Jefe Posición.- Alto Comisario dice por heliógrafo; diga a Jefe posición Nador que espero no tardar dos días en ir y que conviene mucho resista.- Anoche le mandé convoy marítimo que no pudo llegar por impedirlo enemigo; que digan si hay medios de enviar socorros de municiones por mar poniéndose de acuerdo conmigo la realización y día". - Otro; "SD de Sidi Hamed para Nador.- El General Sanjurjo a Jefe posición .- Es posible que esta noche intente con moros amigos de esta kabila a quien se ofrecerá dinero llevar algunos ranchos en frío.- Ya se le dirá el procedimiento y señales que harán". ${ }^{24}$

Por la tarde se acercó un parlamentario para negociar la rendición. Aprovechando su presencia salió uno de los paisanos -José Pérez Sabio- a recoger un cajón de tabaco que le ofrecían los sitiadores. Al volver lo mataron a tiros, lo mismo que al teniente Iglesias que intentó ayudarle. Los sitiados hicieron prisionero al parlamentario.

22 Defensa y evacuación de Nador desde el 22 julio 1921 al 2 agosto siguiente. AGMM. Africa. Leg. 264. carp. 32..

23 Ibid

24 Defensa y evacuación de Nador desde el 22 julio 1921 al 2 agosto siguiente. AGMM. Africa. Leg. 264. carp. 32 . 
El día 27 los sitiadores inutilizaron la tubería del agua dulce, por lo que el suministro de agua se vio reducido a la que podían sacar con la bomba de servicio de las máquinas, que era salada.

Por el heliógrafo se recibió el siguiente despacho:

"S.D..- De Sidi-Hamed para Nador, a las 20-40: El General Sanjurjo a Jefe Posición.- Celebro haya sido poco molestados; quien sabe si estas fortificaciones que hacemos ejercerán influencia.- Una vez bien organizada esta plaza iremos a esa, de modo que ánimo porque los moros van a pesar de su palabra matando y maltratando a los que capitularon.- Les abraza a todos Sanjurjo". ${ }^{25}$

Durante el ataque de esa noche los sitiadores consiguieron estallar un cartucho de dinamita en la pared del horno e intentaron entrar a continuación, siendo rechazados por los guardias civiles que defendían ese frente.

El día 28, el teniente coronel ordenó ocupar la casa del administrador, contigua a la fábrica, a modo de avanzadilla defensiva. El día 29 empezaron a recibir disparos de cañón y por la noche sufrieron un nuevo e intenso ataque en el que los asaltantes intentaron entrar por el piso alto subiéndose a los techos de las cuadras y los hornos. Dos días después, el 31, se reanudaron los ataques con mayor intensidad. Los sitiadores emplazaron un cañón a corta distancia y a lo largo del día llegaron a hacer más de veinte disparos, de los que diez alcanzaron de lleno el edificio causando varias bajas. Por la tarde recibieron un heliograma desde Melilla solicitando informes sobre disponibilidad de municiones, víveres y agua. A la entrada de la noche les llegó una oferta para que se rindiesen y aplazaron las negociaciones hasta el día siguiente. Las negociaciones del 1 de agosto no cuajaron y se intensificó el acoso por la noche. El enemigo había llegado lo suficientemente cerca como para lanzar piedras dentro e intentar amedrentar a los defensores con su griterío. El día 2 amaneció con un fuego intenso por parte de los atacantes; a las 8.40 el teniente coronel enviaba un telegrama al Alto Comisario en el que le anunciaba el repliegue:

“Imposibilitado absoluto resistir más por estado tropas, víveres y municiones. En nombre guarnición ruégole no nos abandone por no poder resistir ni aún esta noche. Puede enviar urgencia la lancha con barcas para intentar embarque; logró empeño jefe rebelde. Entre heridos y enfermos tengo más de cuarenta y cinco bajas. Esperando el fuego de cañón enemigo que aumentará bajas. Espero respuesta de V.E. al aparato". ${ }^{26}$

Pero a las nueve de la mañana se presentó un nuevo parlamentario que mantuvo la oferta del día anterior,

[...] siempre que antes de la una de la tarde se evacuase la casa entregándoseles armamento y municiones, dejándonos marchar libremente hasta el Atalayón acompañándonos cuatro jefes de Kábila como garantía de que no nos ocurriría nada; le exigí nos permitiesen llevar veinte fusiles por lo menos y que ellos trajeran otros veinte

\footnotetext{
25 Ibid.

26 Noticias de Nador. AHN. FC-Tribunal Supremo - Reservado, Exp. 51, N. 5
} 
para nuestra defensa ofreciéndome yo en rehenes si así les parecía conveniente lo que rechazaron por considerarlo inútil.

Antes de tomar una determinación definitiva, convoqué a una reunión al jefe y oficiales, les expuse de una manera clara cual era la situación y les pregunté si consideraban o no llegado el momento de aceptar condiciones que ofrecían los Jefes moros para la evacuación $[\ldots]$;

Un momento después de esta reunión y antes de contestar categóricamente a los moros y aprovechando el ser llamado por el jefe de la harca el comandante D. Juan Almeida autoricé a este para que saliera a conferenciar con él marchando solo al poblado y manifestándome al regreso que el jefe era el llamado Mizian [...].

Aún dudó el jefe que suscribe en resistir o no; pero un heliograma del Alto Comisario en que se le pedía resistiese seis o siete días más, porque antes no se podría llegar a Nador, le hizo comprender que la catástrofe era inevitable e inútil el sacrificio y en su consecuencia aceptó las condiciones que imponía el enemigo. ${ }^{27}$

El heliograma del Alto Comisario había sido el día anterior, pidiéndole que no negociasen con los emisarios moros y que esperasen a que se les avisase por dónde podían hacer la evacuación "que sería muy conveniente demorar seis o siete días que es el tiempo que calculo que tardaré en poder moverme hacia ese poblado" 28 . Como la respuesta al telegrama de las 8.40 no llegaba, el teniente coronel empezó a dar instrucciones para iniciar el repliegue. Ordenó que se inutilizasen la mayoría de los fusiles y que se organizase el transporte de los heridos y enfermos. A las 11.30 todavía no había contestado el Alto Comisario, por lo que se puso en marcha el convoy hacia el Atalayón. Tres cuartos de hora más tarde respondía el Alto Comisario exigiendo al teniente coronel que se mantuviese en su puesto ${ }^{29}$. Lógicamente, Pardo Agudín no recibió el mensaje hasta que la columna llegó a su destino a la 1 del mediodía. Les esperaban en el Atalayón el general Sanjurjo y un destacamento de la Legión. Los heridos y enfermos fueron recogidos en ambulancias y automóviles y el resto siguió andando hasta la segunda caseta. El balance de la resistencia de Nador había sido de 55 bajas, 10 de ellas muertos. Corrochano, el corresponsal de $A B C$, pudo presenciar la llegada de los de Nador:

"Salimos con el Tercio extranjero que iba de servicio de carreteras, a cubrir el sector; en el camino nos enteramos de que algo extraño ocurría; sospechamos que la operación iba a ser importante. Acaso se marchaba sobre Nador. En la Segunda Caseta pedimos permiso al general para ir con las fuerzas.

-¿Pero usted sabe lo que va a ser?

-Se dice que van a Nador.

-Todo lo contrario; los de Nador vienen.

Sanjurjo estaba contrariadísimo. Esperamos.

27 Defensa y evacuación de Nador desde el 22 julio 1921 al 2 agosto siguiente. AGMM. Africa. Leg. 264. carp. 32.

28 Noticias de Nador. AHN. FC-Tribunal Supremo - Reservado, Exp. 51, N.5

29 Noticias de Nador. AHN. FC-Tribunal Supremo - Reservado,Exp.51,N.5: "El cumplimiento del deber exige que continúe V.S. defendiendo su puesto a toda costa, por mi parte me ocupo de organizar el socorro en el momento oportuno" 
A las cinco y media de la tarde llegaban a la Segunda Caseta tres ómnibus automóviles con los enfermos; el resto venía a pie. En el automóvil de Sanjurjo venía el teniente coronel Pardo, jefe de la brigada disciplinaria, gobernador militar de Nador, el que pactó la rendición." 30

A continuación el teniente coronel redactaría el parte que hemos resumido en los párrafos anteriores y que entregó ese mismo 2 de agosto ${ }^{31}$. La prensa de aquellos días trató a los evacuados de Nador como héroes. Y entre los comentarios que se hicieron, surgió alguno que, con el paso del tiempo, daría lugar a una agria polémica:

"Se habló de rendirse, de que les autorizaban a rendirse, se rindieron.

Su sorpresa fue cuando se enteraron por nosotros que habían llegado tropas de España. No podían comprender que hubiera tropas, y en vez de ir a libertarles, les autorizaran a rendirse. Se sentían humillados. Algunos se negaron a que Zegrí -que hizo una interesante información gráfica- les fotografiase." 32

\section{La solicitud de la Laureada}

Para cumplir con los plazos que marcaba el Reglamento de la Orden de San Fernando, el 5 de agosto el teniente coronel Pardo elevaba al comandante general de Melilla, general Cavalcanti, la solicitud de apertura del expediente para la concesión de la Laureada ${ }^{33}$. El general Picasso se encontraba ya en Melilla y había empezado a trabajar. A los pocos días de llegar se le indicó que su tarea "no debe extenderse a los acuerdos, planes o disposiciones del Alto Comisario, concretándose a los hechos realizados por los jefes, oficiales y tropa en las operaciones" ${ }^{34}$ de los días de Annual. Por tanto, como juez militar especial, fueron pasando por su mesa todas las actuaciones judiciales relacionadas con los sucesos de la retirada. Entre otras, llegó la solicitud de apertura de juicio contradictorio para la Laureada del teniente coronel Pardo Agudin. Tras estudiarla, el 8 de septiembre emitió un informe en el que consideraba que había que denegarla porque juzgaba que el teniente coronel no era:

[...] acreedor a dicha recompensa por los méritos de $\mathrm{n}^{\mathrm{o}} 2$ del art 51 del Reglamento de la Orden, que invoca a su favor por cuanto, por los términos de su misma instancia recibió orden expresa de contener en su puesto, tanto la retirada de elementos fugitivos y desordenados, como el avance el enemigo, en su caso, no siendo, por tanto, el primero en reaccionar por propia iniciativa, ni cumpliendo lo demás que preceptúa el apartado. $^{35}$

\footnotetext{
30 ABC, 05/08/1921. Crónica de Corrochano.

31 Defensa y evacuación de Nador desde el 22 julio 1921 al 2 agosto siguiente. AGMM. Africa. Leg. 264. carp. 32.

32 La Correspondencia militar, 05/08/1921.

33 Documentación relativa a Francisco Pardo Agudin. AGMS. Sección 1. Leg P. 440.

34 R.O. 24/08/1921. AHN. FC-Tribunal Supremo - Reservado, Exp. 51, N.3

35 Documentación relativa a Francisco Pardo Agudin. AGMS. Sección 1. Leg P. 440.
} 
Además, añadía que, por lo que se refería a la defensa de la posición, ni cumplió la orden expresa que había recibido el 2 de agosto de resistir unos días más, ni los artículos 20 y 21 de las Ordenanzas Generales para oficiales.

[...] haciendo, opuestamente, indicaciones en orden a ser caso de conciencia, proporcionar medios para evacuarla, y consideraciones inherentes a la esterilidad del sacrificio que se le exigía y las cuales están muy lejos de afirmar la persuasión de agotar los medios extremos de la resistencia a todo trance como correspondía a su deber. ${ }^{36}$

Los artículos del Reglamento de la Laureada ( $\mathrm{n}^{\mathrm{o}} 3$ del art 50, $\mathrm{n}^{\circ} 2$ del art 51) que Picasso consideraba que no cumplía el teniente coronel hacían referencia a la defensa de la posición rechazando las insinuaciones de rendición y la necesidad de ser el primero en reaccionar en caso de depresión moral de las tropas. La decisión definitiva desestimando la petición de Pardo Agudín se hacía oficial el 3 de marzo de 1922 en una Real Orden firmada por el Alto Comisario ${ }^{37}$.

\section{Otros puntos de vista de lo sucedido en Nador}

Además del parte que redactó nada más llegar a Melilla, Pardo Agudín hizo una primera declaración ante el recién nombrado juez instructor de Melilla, el general Miguel Fresneda, al día siguiente de volver de Nador, el 3 de agosto ${ }^{38}$, repitiendo lo que ya había dejado escrito el día anterior. El 20 de agosto fue requerido por el general Picasso - que ya había tomado las riendas de todo el proceso- y se ratificó en su declaración anterior, añadiendo la consideración de que el 20 de julio la compañía de Ceriñola destinada en Nador fue trasladada a Annual, y que con las tropas que contaba no podía hacerse nada eficaz para defender Nador $^{39}$; también repasó el caos que se produjo los días 23 y 24 entre la población civil y los mensajes contradictorios que le fueron llegando esos días. Picasso le preguntó explícitamente si consideraba "apurados los medios racionales de resistencia y llevada esta al extremo último" $" 40$ tal y como le exigían las órdenes del Alto Comisario, las órdenes generales para Oficiales y el honor de las armas, a lo que Pardo Agudín respondió que consideraba que sí. Picasso le llamaría a declarar otra vez más el 7 de noviembre ${ }^{41}$ para preguntarle por el capitán Almansa y por la actuación de la Guardia Civil.

En todo caso, parece que la declaración del 20 de agosto fue la que le sirvió a Picasso para tomar su decisión de denegarle a Pardo Agudín que siguiese adelante el expediente de la Laureada. Hasta la fecha en que Picasso emitió su dictamen sobre la Laureada de Pardo Agudin (8 de septiembre), sólo habían pasado a declarar ante él

\footnotetext{
36 Ibid.

37 Ibid.

38 Diligencias para depurar responsabilidades sobre los hechos ocurridos con motivo del ataque $y$ evacuación del poblado de Nador. AHN. FC-Tribunal Supremo - Reservado, Exp. 51, N.2.

39 Ibid.

40 Ibid.

41 Segunda declaración del testigo. Teniente Coronel Francisco Pardo Agudin. AHN. FC-Tribunal Supremo - Reservado, Exp. 50, N.8.
} 
el padre Alfonso Rey, el 27 de agosto ${ }^{42}$, fray José Antona, el 1 de septiembre y el comandante Almeida y el alférez Pérez, el 3 de septiembre ${ }^{43}$. El capitán Ortoneda -otro de los testigos de lo sucedido en Nador- no prestó declaración hasta el 27 de octubre ${ }^{44}$ y el teniente Fresno no lo hizo hasta mitad de noviembre desde Vitoria ${ }^{45}$; el paisano Vicente Falcó declaró el 21 de noviembre ${ }^{46}$.

Las declaraciones de los testigos que habían estado en Nador coincidían básicamente con lo declarado por el teniente coronel. No obstante, no deja de ser llamativo que se recojan en el resumen del expediente las opiniones tácticas que uno de los frailes, fray José Antona, emite sobre qué habría convenido más en la defensa:

"Hace, empero, constar que durante los tres días posteriores [22, 23 y 24] sólo estuvo ocupado el pueblo por merodeadores, por lo que, si se hubiera dado fusiles a los paisanos, juntamente con la guarnición, se hubiera podido defender durante dicho tiempo y esperar la llegada de auxilios de la plaza." ${ }^{47}$

Opinión que no le importa manifestar al fraile, a pesar de que había salido del poblado en dirección a Melilla el mismo 24 por la noche. De entre las declaraciones relativas a esos primeros días, previos al repliegue hacia la fábrica, Picasso señala dos "hechos reprobables de la retirada" 48 ; uno, que el toque de "llamada" que se hizo para recogerse en la fábrica, produjo no sólo alarma entre los habitantes del pueblo, sino que también sirvió de señal a los moradores de las cabilas cercanas "para lanzarse al robo, saqueo e incendio" 49 . Y no sólo eso, el incendio del depósito de armas sirvió para "precipitar el movimiento sedicioso, hasta entonces contenido" ${ }^{50}$.

Por su parte, el comandante Almeida, consideraba -al contrario que fray Joséque no se hubiese insistido a la Comandancia General en poner antes al poblado en alarma. Añadió, además, que en la mañana del 24 se llevó a cabo la evacuación de Nador, incluidos los 140 enfermos que había en la enfermería militar. ${ }^{51}$ También se le preguntó si era ineludible la capitulación, si se apuraron todos los medios racionales de defensa, si la decisión tomada se correspondía con la situación en la que se encontraban, y si era una decisión honrosa ${ }^{52}$, a lo que Almeida contestó que ya no tenían harina de cebada, que la guarnición estaba extenuada, con la moral de combate casi

\footnotetext{
42 Declaraciones del padre Alfonso Rey. AHN. FC-Tribunal Supremo - Reservado,Exp.51,N.2.

43 Declaraciones de fray José Antona, del Comandante Juan Almeida, del Alférez Lisardo Pérez García. AHN. FC-Tribunal Supremo - Reservado, Exp.51,N.3.

44 Declaración del Capitán Jesús Jiménez Ortoneda. AHN. FC-Tribunal Supremo - Reservado Exp. 50, N.7.

45 Declaración del Teniente Ricardo Fresno Urzay. AHN. FC-Tribunal Supremo - Reservado Exp. 50 , N.9

46 Declaración del testigo paisano Vicente Falcó. AHN. FC-Tribunal Supremo - Reservado. Exp.50,N.8.

47 D. Juan Picasso... Resumen de las actuaciones.... AHN. FC-Tribunal Supremo - Reservado. Exp. 50, N.10. fol 297-298

48 D. Juan Picasso... Resumen de las actuaciones.... AHN. FC-Tribunal Supremo - Reservado. Exp. 50, N.10. fol. 2401

49 Ibid.

50 Ibid.

51 D. Juan Picasso... Resumen de las actuaciones.... AHN. FC-Tribunal Supremo - Reservado. Exp. 50, N.10. fol. 2404

52 Declaraciones del Comandante Juan Almeida. AHN. FC-Tribunal Supremo - Reservado, Exp.51,N.3. Fol 511-517
} 
perdida y que había llegado un buen número de refugiados de otras posiciones, por lo que no era posible continuar con la defensa. Por otra parte, afirmó, había que tener en cuenta que la casa no reunía condiciones para la defensa y que estaban empezando a recibir fuego de artillería. En definitiva, consideraba "cumplidas así las Órdenes generales para oficiales, como las particulares para el caso y salvado el honor de las Armas" $"$.

El Consejo Supremo de Guerra y Marina en sus actuaciones relativas al expediente Picasso, respecto a la capitulación de Nador consideró que el teniente coronel tenía que haber esperado a que el Alto Comisario le avisase "de cuándo y cómo podía hacer la evacuación, que 'sería muy conveniente demorar seis o siete días', que era lo que calculaba tardaría en poder moverse hacia el poblado" 54 . No deja de llamar la atención que al valorar estas actuaciones, no se haga alusión al calendario que finalmente se llevó a cabo en las operaciones de reconquista: los avances iniciales no comenzaron hasta el 12 de septiembre y Nador no sería reconquistado hasta el 17 de septiembre, un mes y medio después de ser evacuado.

A pesar de que las declaraciones de los distintos testigos coinciden en los hechos esenciales, sin embargo, su peso, sus matices, y sus correspondientes efectos, son diversos según quien haga la interpretación, el general Picasso, sus fiscales, o el Consejo Supremo. Se pueden llegar a encontrar tantos hechos reprobables como "juzgadores" hubo de aquellos acontecimientos.

\section{El consejo de guerra}

Las tareas del general Picasso en Melilla no se limitaron a investigar lo sucedido en Annual: tenía jurisdicción para investigar cualquier hecho ocurrido aquellos días que pudiese constituir delito ${ }^{55}$. Consideró que la actuación del teniente coronel podía haber sido delito y ordenó que se le instruyese un consejo de guerra. Aunque la tramitación era de urgencia, hasta enero de 1922 no se constituyeron la auditoria y fiscalía, y en julio de 1922 sólo se había resuelto uno de los 58 procesos iniciados en Melilla ${ }^{56}$.

Por otra parte, la presentación del expediente Picasso en el Congreso reactivó la tramitación de los procesos, pero introduciendo nuevos cargos que quizá no estuviesen contemplando los consejos de guerra. El fiscal, en las conclusiones que había elevado al Consejo Supremo de Guerra y Marina el 26 de junio de 1922, incluía una lista de personal que consideraba que había actuado de manera punible; entre ellos estaba el teniente coronel Pardo Agudín, del que pensaba que había incurrido en los casos del artículo $295-1^{\circ}$ del Código de Justicia Militar y el artículo 762 del Regla-

53 Ibid.

54 Informe del fiscal militar. Nador, Zeluán y Monte Arruit. AHN. FC-Tribunal Supremo - Reservado, Exp. 51, N.22. Fol 57.

55 Relación de las causas instruidas en la Comandancia General de Melilla. AHN. FC-Tribunal Supremo - Reservado, Exp. 51, N.29. Fols 4-7.

56 LA PORTE, Pablo: El desastre de Annual..., p. 538. 
mento para el servicio en campaña ${ }^{57}$. Finalmente el consejo de guerra contra el teniente coronel se instruyó "por su actuación en la defensa, capitulación y evacuación de Nador con motivo de los sucesos de julio de 1921"58. El artículo 295 del Código de Justicia Militar hablaba de la capitulación punible, mientras que el artículo 762 del Reglamento para el servicio en campaña decía que todo gobernador de una plaza que se hubiese rendido tendría que presentar los datos y documentos -entre ellos las actas de la Junta de Defensa- que justificasen esa decisión. Como se ve, los posibles delitos que estima el fiscal, son distintos de las actuaciones que Picasso consideraba punibles cuando tuvo que firmar la denegación para la Laureada.

En la sentencia del consejo de guerra se fueron valorando tanto las circunstancias que Picasso había considerado como las que había señalado el fiscal. En las consideraciones y resultandos de la sentencia y en el dictamen del auditor fueron saliendo de una forma u otra. Se podría decir para este caso, lo que apuntaba Rodríguez de Viguri en su defensa del General Navarro: la natural tendencia de los Fiscales a formular juicios condenatorios que les lleva

"[...] a acumular contradicciones, pues el mismo hecho que le sirve para acusar a uno se presenta interpretado en forma diversa cuando con él puede deducirse alguna responsabilidad contra el otro procesado." ${ }^{99}$

En el expediente, Picasso censuraba el hecho de que el jefe de la circunscripción de Nador residiese en Melilla ${ }^{60}$; sin embargo en la sentencia se decía que estaba autorizado a ello y que, precisamente por eso, pudo acudir a la reunión de jefes que se convocó para afrontar la situación en los primeros días. Por otra parte, habría que pensar si era estrictamente necesario que el jefe de la unidad tuviese que residir en Nador, un enclave muy a retaguardia, con una dotación de unos 200 hombres dedicados a tareas prácticamente burocráticas, al que podía llegarse desde Melilla en 20 minutos. En cuanto a la orden de mantener la posición, uno de los puntos sobre los que basculaba la decisión de Picasso, y que el fiscal consideraba como constitutivo de delito, el dictamen del auditor del consejo de guerra decía:

"[...] que según el autorizado parecer técnico militar del Consejo antes de capitular se emplearon todos los medios de defensa exigidos por las leyes del honor y del deber $[\ldots]$ pues resistieron eficazmente el ataque y asalto del enemigo muy superior en número durante nueve días, no obstante las malas condiciones defensivas de la fábrica, habiendo sido objeto de fuego, incluso de artillería que produjo destrozos en el edificio, con muy deficiente alimentación y bebiendo agua salobre en la mayor parte de

57 Informe del fiscal militar. Nador, Zeluán y Monte Arruit. AHN. FC-Tribunal Supremo - Reservado, Exp. 51, N.22. Fol 53-62.

58 Ibid.

59 RODRÍGUEZ DE VIGURI Y SEOANE, Luis: La retirada de Annual y el asedio de Monte Arruit. Escrito en defensa del general don Felipe Navarro y Ceballos-Escalera, Barón de Casa Davalillo, leído ante el Consejo Supremo de Guerra y Marina, reunido en sala de justicia. Sucesores de Rivadeneyra. Madrid. 1924, pp. 7-8.

60 Informe del fiscal militar. Nador, Zeluán y Monte Arruit. AHN. FC-Tribunal Supremo - Reservado, Exp.51, N.22. Fol 53-62 
los días, habiendo tenido bajas de muertos y heridos en proporción superior a la cuarta parte de las fuerzas sitiadas y sin esperanzas de ser a tiempo socorridos, después de no haber accedido a varias intimaciones del enemigo, fue cuando, unánime la opinión del Consejo de defensa en considerar imposible prolongar más tiempo la resistencia." 61

El general Picasso, en el resumen que había enviado al Consejo Supremo, ya había señalado que había reclamado algunas órdenes (en concreto sobre el establecimiento de la defensa en la fábrica de harinas) a la Comandancia general y que, con fecha 1 de septiembre, le habían contestado que no se le había dirigido al teniente coronel ninguna orden escrita, y que sólo habían tenido con él algunas conversaciones telefónicas ${ }^{62}$. Desde el punto de vista de la estricta transmisión de la orden, es decir, por escrito (o recogida por escrito del correspondiente parte heliográfico) y de la explicitación de su contenido, estaba claro que la única que había recibido era la que le dieron al llegar a las propias líneas: "la única que se le puso ordenándole la conservación del puesto, llegó al Atalayón cuando ya habían evacuado la fabrica" ${ }^{63}$. No existían -porque no se habían dado- órdenes anteriores explícitas al respecto. Y la única que se había dado, había llegado tarde.

Considerando-Que hasta esta última comunicación no hubo orden concreta de mantenerse en Nador hasta perder la vida, pues las recibidas no envolvían mandato terminante de hacerlo, y demostraban por el contrario que el mando no era opuesto absolutamente a la evacuación, por lo cual no puede estimarse que tales hechos, digo haya existido el delito de desobediencia que se menciona en la diligencia de procesamiento. ${ }^{64}$

Otros "considerandos" de la sentencia argumentaban que no había delito de negligencia, ya que ante el reiterado ofrecimiento de refuerzos, no parecía que hubiese sido necesario tomar más medidas defensivas que las que tomó el teniente coronel. Además, por la forma y rapidez con que sucedió todo, tampoco hubo tiempo para recoger más alimentos y municiones que los que se recogieron para acogerse a la fábrica de harinas. Por otra parte, lo numeroso del enemigo y la disponibilidad de artillería que tenía, hacían imposible sostener la posición.

Tras esos "considerandos", el consejo de guerra absolvía al teniente coronel el 22 de septiembre de 1924; el auditor consideraba la sentencia absolutoria conforme a derecho y la tramitaba para que se hiciese oficial el 3 de octubre; el 9 de octubre firmaba Sanjurjo el decreto de conformidad con la sentencia y el 11 de octubre se le comunicaba al teniente coronel ${ }^{65}$.

Mientras Pardo Agudín esperaba la decisión del consejo de guerra, continuó destinado en Melilla como jefe de la brigada disciplinaria y comandante militar de Nador. En enero de 1923 quedó como disponible en Melilla hasta que se pronunció la sentencia, lo que le permitió solicitar un cambio de residencia que le llevó los dos años

61 Documentación relativa a Francisco Pardo Agudin. AGMS. Sección 1. Leg P. 440.

62 Informe del fiscal militar. Nador, Zeluán y Monte Arruit. AHN. FC-Tribunal Supremo - Reservado, Exp.51,N.22. Fol 53-62

63 Documentación relativa a Francisco Pardo Agudin. AGMS. Sección 1. Leg P. 440.

64 Ibid.

65 Ibid. 
siguientes primero a la Coruña, después a Madrid y más tarde a Zamora y Logroño. Finalmente en otoño de 1925 volvió a Madrid con graves problemas de salud, que dieron finalmente con él en la tumba el 13 de octubre ${ }^{66}$.

\section{La campaña de reconquista. Militares vs. militares}

A lo largo de esos meses de espera el teniente coronel pudo ver como la percepción de los sucesos de Marruecos por parte de la opinión pública iba convirtiéndose en un agitado vaivén en el que se confrontaban y discutían los criterios militares respecto a la campaña de reconquista y la actuación de España en Marruecos, se evaluaban los debates políticos en torno a las responsabilidades, y se manifestaban los celos y disputas poco disimuladas entre los militares de las Comisiones Informativas y sus antagonistas.

Los planteamientos de las Comisiones Informativas obtuvieron el visto bueno de buena parte de los medios de opinión, que querían ver en ellas síntomas de regeneracionismo. Buena parte de la población también consideraba que sus reivindicaciones tenían sentido y las veía con buenos ojos. Al cabo de un par de años habían conseguido uno de sus principales objetivos: la supresión de los ascensos por méritos de guerra; sin embargo eso no supuso su desaparición sino todo lo contrario: pasaron a incorporarse a la estructura del Ministerio de la Guerra, en donde su opinión contaba para la toma de determinadas decisiones. De esta manera acabaron convirtiéndose en un grupo de presión dentro del Ejército que, por su propia naturaleza tenía como oponentes a los militares conocidos como "africanistas". Y los sucesos de Marruecos fueron los que, abiertamente, desencadenaron el enfrentamiento entre ambos grupos de militares.

En los primeros momentos algunos echaron sobre las Comisiones Informativas parte de la responsabilidad del Desastre; se criticó abiertamente el comportamiento que habían tenido en aquellos días algunos de los jefes y oficiales afectos a las Comisiones; también se adujo que al haber impuesto el turno obligatorio para los destinos en África de jefes y oficiales, habían restado eficacia al Ejército; igualmente se les echó en cara que, a pesar de que había sido una de sus primeras reivindicaciones, ni la instrucción de los batallones que venían de la península había mejorado, ni tampoco los medios técnicos de los que disponía el Ejército ${ }^{67}$.

Las desavenencias entre unos y otros empezaron a manifestarse casi inmediatamente. En cuanto comenzaron las actuaciones de Picasso, se presentaron en Melilla algunos representantes de las Comisiones con la intención de "proteger" a los suyos y criticar veladamente a los africanistas ${ }^{68}$. El comienzo de las operaciones de reconquista dio lugar a más roces: el 29 de septiembre, el día del "convoy a Tizza", El general Berenguer, que había presenciado la operación, ordenó abrir expediente

\footnotetext{
66 Ibid.

67 LA PORTE, Pablo: El desastre de Annual y..., pp. 310 y ss.

68 BALFOUR, Sebastian: Abrazo mortal. De la guerra colonial a la guerra civil en España y Marruecos (1909-1939), Barcelona, Península, 2002, p. 320; LA PORTE, Pablo: El desastre de Annual..., p. 310; MADARIAGA, María Rosa: En el barranco del lobo..., p. 301.
} 
al general Tuero y a los coroneles Lacanal y Sirvent. Las Comisiones Informativas presionaron sobre el ministro de la Guerra para que no se llevasen a cabo esos encausamientos y ganaron el pulso. No se les relevaría hasta que no se completara el expediente sobre ellos. Por su parte, el general Tuero minimizaría más adelante ante la prensa la intervención de Cavalcanti en Tizza. La tensión aumentó dos semanas después cuando el general Cabanellas a la vista del espeluznante panorama que se le presentó al ocupar Zeluán, envió una nota a la prensa en la que responsabilizaba del Desastre a las Comisiones. Estas reaccionaron consiguiendo que en noviembre se disolviese su Brigada de Caballería, y él quedase como disponible.

El 20 de octubre de 1921 tuvo lugar la apertura de las Cortes con Annual como tema central ${ }^{69}$. Así lo recordaba años más tarde Indalecio Prieto:

\begin{abstract}
“Algo más dijimos los diputados que fuimos a Melilla: Lazaga, Solano, el marqués de la Viesca y yo, especialmente yo porque libre de ataduras con partidos monárquicos, mi libertad era absoluta, y por haber podido documentarme mejor. Impresionando a la Cámara sorprendí al Gobierno con cifras exactas de los millares de bajas sufridas, cifras ignoradas por él , a causa de que la Comandancia de Melilla, en el desbarajuste reinante, no se cuidó de comunicárselas". ${ }^{70}$
\end{abstract}

Algunos de los diputados responsabilizaron a las Comisiones de lo sucedido: por sus coacciones, su imposición del turno obligatorio, su ineficacia en la mejora del material, su influencia en el reblandecimiento de la moral, su burocratismo. Por su parte, la Correspondencia Militar, órgano de opinión de las Comisiones reaccionaba el 21 de octubre dando un "grito de alarma" (así subtitulaba su editorial "Sobre las Juntas de Defensa") y afirmando que

\begin{abstract}
“...se han multiplicado con portentosa tenacidad e innegable habilidad los esfuerzos necesarios para hacer a las Juntas un ambiente cada vez más hosco, más contrario en el seno de la opinión pública, y a la hora de la escénica preparación de cuanto estamos contemplando ayer y hoy en el Congreso de los Diputados, se vislumbra bien el extenso frente de combate que se ha formado para rendir y pisotear estos organismos", llegando a afirmar el editorial que se estaban sembrando "los gérmenes de una pavorosa guerra civil". ${ }^{71}$
\end{abstract}

Hubo un nuevo enfrentamiento entre el ministro de la Guerra y las Comisiones a comienzos de diciembre por el proyecto de recompensas para jefes y oficiales que habían intervenido en la campaña de reconquista. Las Comisiones exigieron que no hubiese recompensas hasta que no se averiguasen responsabilidades y que la depuración de responsabilidades alcanzase a toda la jerarquía militar. La ruptura definitiva entre las Comisiones y la Cierva tuvo lugar por entonces. Cavalcanti fue destituido como Comandante General de Melilla por unas declaraciones a la prensa y le sustituyó Sanjurjo, general de Brigada con menor graduación y antigüedad que otros que

69 PANDO DESPIERTO, Juan: Historia secreta de Annual, Madrid, Temas de Hoy, 1999, pp. 190-193.

70 PRIETO, Indalecio: Convulsiones de España..., p. 22.

71 La Correspondencia Militar, 21/10/1921 
había en la plaza. Después de las primeras críticas, el ministro de la Guerra se mantuvo en su decisión y las Comisiones rompieron decididamente en contra suya. La Correspondencia Militar arremetió con virulencia contra él en los últimos días de 1921.

Pero la irritación y el malestar dentro del Ejército no sólo procedían de la pugna entre "junteros y africanistas". Los sucesos de Annual contribuyeron a que se revelasen agrias celotipias entre diversos mandos castrenses. Algunas se manifestaron a través de declaraciones o artículos en prensa de generales ya antiguos o alejados del territorio africano que, probablemente, buscaban un puesto de mando allí; Weyler y Burguete, entre otros, criticaron abiertamente la gestión militar que se había llevado en Marruecos. Ante estos incidentes y el ambiente polémico que se estaba empezando a fraguar, el 21 de agosto el ministro de la Guerra publico una Real Orden en la que prohibía comentarios públicos y críticas a las operaciones ${ }^{72}$.

También hubo controversia a cuenta de la designación de los jefes que habían de llevar las riendas del Ejército en la reconquista del territorio perdido. El general Burguete se quejó de que se hubiese nombrado a Cavalcanti como Comandante General de Melilla, cuando él era de mayor antigüedad. Cabanellas también era más antiguo y también se mostró en desacuerdo, pero siguió con su puesto en Melilla a las órdenes de Cavalcanti.

\section{El socorro a Nador, Zeluán y Monte Arruit}

Pero no solo fue eso. Las desavenencias se extendieron también a cuestiones de criterio, a las soluciones estratégicas y tácticas que se habían tomado o se habían dejado de hacer. Ese fue el caso del socorro de Nador y Monte Arruit. Antes se han mencionado los debates que hubo en las sesiones de apertura de las Cortes en octubre de 1921. En todos ellos apareció en un momento u otro el tema del socorro a Nador (a Nador, Zeluán y Monte Arruit), lo que indica lo presente que estaba en el ambiente la polémica de si se pudieron socorrer o no esas tres posiciones que habían quedado aisladas. Este punto es importante porque constituyó uno de los motivos que se adujo para denegarle el curso al expediente para la Laureada a Pardo Agudín, y también uno de los puntos centrales de su consejo de guerra.

Aparte de los comentarios que se hicieron en la prensa, contribuyeron a avivar la polémica algunas declaraciones del coronel Riquelme. En diversas ocasiones, ante la prensa y ante la Comisión de Responsabilidades del Congreso manifestó que en su día había dicho a los generales jefes presentes en Melilla que se podía ir en auxilio de Nador y que él se comprometía a llevar una columna hasta allí ${ }^{73}$. Sin embargo, los generales Sanjurjo, Cabanellas, Berenguer, en sucesivas declaraciones a lo largo de los meses siguientes -Berenguer y Cabanellas específicamente ante la Comisión de

72 LA PORTE, Pablo: El desastre de Annual y la crisis de la Restauración en España (1921-1923). Tesis doctoral, Madrid, Universidad Complutense, 1997, 315. En la nota 121 reseña 7 intervenciones del general Burguete en la prensa nacional entre el 30 de julio y el 16 de agosto.

73 Cfr. por ejemplo, El Sol 06/05/1922; De Annual a la República. La comisión de responsabilidades (Morata, 1931), 178-179. 
Responsabilidades- ${ }^{74}$, negaron que se hubiese producido tal manifestación por parte de Riquelme, y señalaron que a comienzos de agosto se había celebrado una junta de generales y se había desistido de ir a socorrer Monte Arruit porque, en palabras de Berenguer:

"En la fecha que cita Riquelme, yo contaba con 16 batallones; nueve de ellos estaban destacados, y con los siete restantes había de atender a la defensa de la plaza. Lo más que podía haber dedicado a columna móvil eran tres batallones; es decir unos 1.500 hombres, quintos en su mayoría". ${ }^{75}$

Asimismo, tanto Berenguer como Cabanellas consideraron ante la comisión de Responsabilidades que había medios suficientes en Nador para prolongar la resistencia.

Por otra parte, las opiniones de los enviados de prensa y los diputados que visitaron Melilla en aquellos momentos, coincidían en que la seguridad de la plaza no ofrecía garantías suficientes como para intentar la salida de una columna en socorro de las posiciones ${ }^{76}$. Berenguer, en su intervención en el Senado del 14 de julio de 1923 con motivo del suplicatorio que se siguió para poder proceder contra él, insistió en los mismos datos respecto a las fuerzas disponibles hacia el "4 ó 5 de agosto", aunque añadía que esos eran los efectivos de Infantería y que "había, además, las banderas de la Legión y los tabores de Regulares, que formaban unos 1500 hombres que había traído de Ceuta, y la gente que se había podido reunir en la plaza, que eran unos 2000 ". Pero con todas esas fuerzas había que cubrir todo el frente posiciones en torno a Melilla. Para corroborar sus afirmaciones habló de la junta de generales que tuvo lugar el 6 de agosto y leyó el acta que se levantó de ella ${ }^{77}$.

En cuanto al enfrentamiento entre Sanjurjo y Riquelme, llegó a su punto culminante con motivo de la operación de Tugunz, el 30 de marzo de 1922. Riquelme fue cesado como jefe de la policía indígena, pues se consideró que las informaciones que había aportado habían sido tan equivocadas que habían estado a punto de provocar una derrota. Sin embargo, Riquelme lo consideró un agravio personal por parte de Sanjurjo e hizo unas declaraciones en prensa hablando no sólo de la operación de Tuguntz, sino también recordando los días de Annual, su disposición de acudir en ayuda de Monte Arruit y la negativa de Sanjurjo y el resto de los generales a hacerlo. Sanjurjo respondió con unas declaraciones que fueron publicadas en El Sol del 20 de mayo: "no considero a Riquelme con la vista ni con la presencia de ánimo suficiente para haber ido entonces a Monte Arruit"; ante esas palabras Riquelme comenzó las

\footnotetext{
74 De Annual a la República. La comisión de responsabilidades. Morata, 1931, pp. 281-294, declaraciones de Cabanellas; pp. 295-336, declaraciones de Berenguer.

$75 A B C, 18 / 05 / 1923$

76 PRIETO, Indalecio: Con el Rey o..., p. 27-29: "La verdad sobre la situación” es una crónica desde Melilla el 9 de septiembre donde comenta la difícil situación en la que todavía se encuentra Melilla. También Ortega y Gasset en sus crónicas de agosto-septiembre de 1921 deja bien clara esa cuestión.

77 Diario de sesiones. Senado. 14/07/1923. P. 1747
} 
gestiones para que la cuestión fuese zanjada en un tribunal de honor que, finalmente, resolvió el 5 de junio de $1922^{78}$.

Se ha estudiado con profundidad las cuestiones concernientes a las responsabilidades de Annual y sobre cómo dicho debate contaminó la sociedad española la época. Sin embargo la historiografía no acaba de concederle el peso que tuvo como desencadenante del proceso político que acabó con el régimen de la Restauración, que, a su vez, dio lugar a todo lo que vino después que acabó en guerra civil y en una dictadura de cuarenta años. Indalecio Prieto, cuya autoridad al respecto -como observador de primera línea, político incisivo y decisivo en aquellos días y analista de lo sucedido después- es indiscutible lo dice de la siguiente manera:

"Las Juntas militares de Defensa abrieron en 1917 la primera grieta en el régimen monárquico. Esa, como las sucesivas cuarteaduras y el derrumbamiento final provinieron de África. Marruecos acabó con la monarquía y ha estado a punto de acabar con España...."79

Por su parte, Pando añade otra perspectiva, insiste en otros matices, sitúa el peso de la responsabilidad en otro lugar, pero mantiene, en lo esencial, su origen:

"La antorcha por las responsabilidades de lo ocurrido en Marruecos pasaría al Parlamento -Comisiones de los llamados "Diecinueve" (1922) y "Veintiuno" (1923)-, mientras Picasso volvía a sus labores en la Sociedad de Naciones. De allí regresaría para encontrarse con un cambio de régimen y el impunismo alzado al poder. Había sido decretado, al unísono, por el primorriverismo impulsivo y el alfonsismo complaciente. Ese impunismo socavó el edificio monárquico hasta hacerlo caer. ${ }^{80}$ "

De alguna manera, el ambiente dentro del Ejército y en la opinión pública durante aquellos meses, encontró su reflejo en el dictamen realizado por Picassso sobre la actuación de Pardo Agudín en Nador. ¿Podía haber resistido más? Algunos de los que opinaron desde fuera dijeron que síri ${ }^{81}$; él y los oficiales que estaban con él, tuvieron claro que no. ¿Recibió orden expresa de resistir y hacerlo hasta el límite? No. Hubo comunicaciones del comandante general de Melilla y del general Sanjurjo, pidiendo que resistiesen unos días más, pero llegaron tarde.

Picasso recoge en su investigación las comunicaciones que el teniente coronel había señalado en su declaración: el día 26 recibió "un despacho del general Sanjurjo transmitiendo el aviso del Alto Comisario de "que espero no tardar dos días en ir y

78 HERNÁNDEZ DE HERRERA, Carlos, GARCÍA FIGUERAS, Tomas: Acción de España en Marruecos; 1492-1927, Madrid, Imp. Municipal, 1929-1930, p. 408. Se recoge el acta.

79 PRIETO, Indalecio: Convulsiones de España..., p. 49.

80 PANDO DESPIERTO, Juan: Historia secreta de ..., p. 199. Ya hemos citado al comienzo del trabajo la reciente obra dirigida por ARAGON REYES, Manuel: El Protectorado español en ... Su tercer volumen donde se trata "La vertiente histórico-política" y "La vertiente militar", aborda de nuevo el tema con opiniones tan autorizadas como las de Juan Pando Despierto, María Rosa de Madariaga o Santos Juliá.

81 De Annual a la República. La comisión de responsabilidades (Morata, 1931), p. 332. En su declaración, Berenguer dice "Nador se pudo haber socorrido. Precisamente estábamos o mejor dicho, empezábamos a estar en condiciones de poder atender a Nador cuando se rindió inopinadamente" 
conviene resista" 82 ; y que el 1 de agosto el Alto Comisario le pedía "que esperase, por tanto, a recibir aviso de cuándo y cómo podía hacer la evacuación, que "sería muy conveniente demorar seis o siete días" ${ }^{83}$. Por su parte el fiscal llama la atención sobre "esa cadena de conferencias con el Ministro del Alto Comisario, cuya actuación, para el fiscal, resulta inexplicable..." 84 . Un último dato que podemos añadir, para completar el panorama de órdenes y "no-órdenes" que se dieron o dejaron de dar, es el telegrama enviado a Zeluán el 31 de julio en el que el Alto Comisario indicaba al jefe de posición: "si está en condiciones de evacuar ese puesto, hágalo sobre la Restinga." 85 .

\section{La viuda de Pardo Agudin retoma el expediente}

A pesar de todos los comentarios y perspectivas que bullían en el Ejército y en la opinión pública respecto a la actuación y la reacción de Pardo Agudín en Nador, el consejo de guerra lo absolvió el 22 de septiembre de $1924^{86}$. Para entonces llevaba un año gobernando Primo de Rivera, que había dado su golpe de estado, precisamente, al amparo de la deriva que había tomado la exigencia de responsabilidades por lo de Annual. Aunque en su manifiesto hablaba de buscar una solución al problema de Marruecos, su disposición, más que de conquista militar, era de contemporización con las cabilas. Finalmente acabó decidiéndose por la ocupación militar.

Por otra parte, Primo de Rivera impuso criterios restrictivos a la concesión de recompensas, hasta el punto de que en abril de 1925 se publicó un nuevo Reglamento de recompensas en tiempo de guerra ${ }^{87}$, y en diciembre también era modificado el Reglamento de la orden de San Fernando ${ }^{88}$. No es de extrañar, por tanto, que los expedientes fuesen revisados con detenimiento por fiscales y por el Consejo Supremo de Guerra y Marina, y que cualquier defecto, aunque fuese de forma, sirviese de argumento para denegar la petición. En la ley de bases para la reorganización del Ejército de $1918^{89}$ se habían establecido como recompensas por méritos de guerra la Cruz del Mérito Militar con distintivo rojo, la Medalla Militar y la Cruz Laureada de San Fernando, además del ascenso al empleo inmediato. En esa reorganización se suprimían las recompensas a las acciones distinguidas en la Orden de San Fernando, que eran sustituidas por la Medalla Militar, y se conservaba únicamente la Cruz Laureada. Ya hemos comentado que en 1920 se publicó un Reglamento de recompensas de acuerdo con esas bases, y en 1925 otro nuevo ${ }^{90}$.

\footnotetext{
82 Noticias de Nador. AHN. FC-Tribunal Supremo - Reservado, Exp.51,N.5. Fols 1545-1550.

83 Ibid.

84 Informe del fiscal militar. Nador, Zeluán y Monte Arruit. AHN. FC-Tribunal Supremo - Reservado, Exp. 51, N.22. Fol 58.

85 Ataque y defensa de Zeluán desde el 22 de julio. AGMM. Africa. Leg 264, carp. 31.

86 Documentación relativa a Francisco Pardo Agudin. AGMS. Sección 1. Leg P. 440.

87 Gaceta de Madrid, 1925, nº 102.

88 Gaceta de Madrid, 1925, no 336.

89 Gaceta de Madrid, 1918, n 181. Bases para la reorganización del Ejército.

90 Gaceta de Madrid, 1920, N 74; en 1925 se dieron nuevas bases para la concesión de recompensas en tiempo de guerra Gaceta de Madrid 1925, nº 76.
} 
Pardo Agudin, una vez resuelto el consejo de guerra, fue pasando por distintos destinos en la península a lo largo del año siguiente. En otoño de 1925, estando en Madrid, falleció sin haber vuelto a preocuparse por la Laureada. Quizá pensase que el consejo de guerra le había cerrado cualquier opción. Sin embargo, a las pocas semanas de su muerte, en noviembre de 1925, su viuda se decide a solicitar la apertura del juicio contradictorio para la concesión de la Laureada; en ella sostiene que la petición de la Laureada se había desestimado fundamentándose en un informe emitido por el general Picasso y añade:

"Que: ignorando las razones aducidas (tanto por el mando como por el Excmo. Señor General Picasso) para fundamentar la negativa de un derecho concedido clara y terminantemente en los artículos cuarenta y uno y cuarenta y tres del Reglamento mencionado, supuso que tuvieran su fundamento en la creencia o posibilidad de que le alcanzara al esposo de la recurrente alguna responsabilidad por los sucesos desarrollados en Melilla durante el mes de julio de mil novecientos veintiuno.

"Que: el consejo de guerra de oficiales generales en Melilla el veintidós de septiembre de mil novecientos veinticuatro, dictó sentencia absolutoria en la causa que se le siguió a su esposo por su actuación en los referidos sucesos, sentencia hecha firme por la autoridad judicial en aquel territorio con fecha nueve del siguiente mes, quedando por lo tanto, su absoluta irresponsabilidad y desapareciendo las únicas razones que pudiera haber alegado el juez especial Excelentísimo Señor General Picasso para emitir el informe que se pidió.

Que en virtud de lo que antecede y creyéndose con derecho a lo que solicitaba ya que lo hizo en el plazo que marca el artículo treinta y nueve y al amparo de los cuarenta y uno y cuarenta y tres del Reglamento de la Real Militar Orden de San Fernando, a V.M.

Suplica se digne concederle la revocación de la Real Orden Manuscrita del tres de abril de mil novecientos veintidós y en su consecuencia la apertura del expediente de juicio contradictorio para la cruz de San Fernando a su finado esposo." 91

La instancia sigue su itinerario hasta el Consejo Supremo de Guerra y Marina. En marzo de 1926 ya hay un primer informe favorable del fiscal: "el Fiscal Militar estima que procede pase esta instancia al General Jefe del Ejército de España en África para que dicha autoridad ordene la formación del expediente" ${ }^{22}$. El fiscal togado suscribió el informe y el Pleno del Consejo Supremo de Guerra y Marina dio su conformidad con fecha 4 de marzo y lo envío al ministerio de la Guerra para que continuase su tramitación. El expediente se envió al general jefe del Ejército de España en África para que lo tramitase y la resolución del juez instructor llega el 6 de junio de 1926; en ella consideraba que podía "accederse a lo solicitado por la viuda del teniente coronel de Infantería fallecido Don Francisco Pardo Agudín”"93.

\footnotetext{
91 Documentación relativa a Francisco Pardo Agudin. AGMS. Sección 1. Leg P. 440.

92 Ibid.

93 Ibid.
} 


\title{
10. Un héroe fuera de plazo no es héroe
}

El expediente volvió de nuevo al Consejo Supremo a finales del verano. El pleno de dicha institución, que seguía formado por las mismas personas que en marzo, acabaría denegando la petición de la viuda de Pardo Agudín sobre el nuevo dictamen del fiscal militar que lo fundamenta de la siguiente manera:

\begin{abstract}
"A partir de esa fecha [el 11 de octubre de 1924, cuando se le comunicó la sentencia del consejo de guerra], y habiendo quedado sin efecto las causas que motivaron el que fuera desestimada su primera instancia, pudo el teniente coronel Pardo, formular nuevamente su petición habiendo tenido tiempo sobrado para ello, puesto que consta que no falleció hasta el 13 de octubre del año 1925, es decir un año después de la fecha apuntada, habiendo ejercido en todo este periodo los servicios propios de su empleo. Si no hizo uso del derecho que por el Reglamento tenía, indudablemente y por motivos sólo de él conocidos, renunció a aquél, siendo por lo tanto un derecho que perdió por no ejercerlo a tiempo, sin que, por otra parte, aparezca en el expediente causa ninguna que le haya impedido usarlo, ni en el antedicho derecho puede hacerse valer al ocurrir el fallecimiento del interesado por la viuda del mismo, puesto que prescribió antes de ocurrir su muerte." 94
\end{abstract}

\section{Conclusiones}

Los tiempos convulsos que siguieron al desastre de Annual condicionaron la vida social y política española hasta el punto de que puede decirse que se convirtieron en el germen de lo que sucedería en España en los decenios siguientes. La escalada en la discusión de las "responsabilidades" lo llenó todo, y quienes habían estado en primera línea de combate lo sufrieron especialmente. A la lógica propia de la justicia militar que se les aplicó, vieron cómo se les sumaba una jurisdicción especial en manos del general Picasso, después, unas comisiones parlamentarias que, a medida que profundizaban en las responsabilidades (y las ampliaban), insistían en los errores y torpezas que se habían cometido; a ello se sumaba la intervención del Consejo Supremo de Guerra y Marina, el más alto tribunal militar. Los juicios que emitieron cada una esas instancias se vieron condicionados por el estado de la opinión pública, por los intereses políticos que había en juego, o por sus propios intereses (o miedos) personales, de tal manera que se puede decir que la estricta justicia de las decisiones que se tomaron fue el último criterio al que se atendió. De acuerdo con esos presupuestos, se puede entender que cuando se tuvo que tomar la decisión de concederle la Laureada el teniente coronel Pardo Agudín por su actuación en la defensa de Nador, el tribunal optase por lo que menos problemas le podía traer: denegársela por estar fuera de plazo. Prevaleció, por tanto, el criterio burocrático sobre el sentido propio de la recompensa: el valor en combate.

\footnotetext{
94 Ibid.
} 